See Article page 528.

\section{Commentary: Continuous steady development is made by taking 2 steps forward, 1 step back}

\author{
Masato Mutsuga, MD, ${ }^{\mathrm{a}}$ and \\ Toyofumi F. Chen-Yoshikawa, MD
}

In cardiac surgery, myocardial protection by using a sufficient dose of cardioplegia is essential when performing a cardiac procedure. Subsequently a cardioplegia infusion every 20 to 30 minutes during surgery is standard practice, which interrupts the important procedure. del Nido cardioplegia (DNC) was developed in the early 1990s and it has been widely used because it has several advantages. Although the original protocol stated that subsequent doses were not required within 180 minutes after the initial infusion, ${ }^{1}$ subsequent doses of DNC have been administered after 90 minutes of the aortic crossclamp based on expert opinions-not based on any experimental evidence. ${ }^{2}$ Therefore, Jung and colleagues ${ }^{3}$ decided to perform this study on extracted human hearts at heart transplantation. There are more patients who require cardiac surgery with an aortic crossclamp than those receiving a heart transplantation, which means a relatively small number of patients would help to establish specific evidence regarding the safe ischemic time for sufficient myocardial protection, to the benefit of the broader sector of cardiac surgery. In this sense, Jung and colleagues ${ }^{3}$ should be highly lauded for performing this research.

There are several weak points in this study. Firstly, the authors showed how the human heart is damaged over time after a single-dose DNC infusion. However, they

\footnotetext{
From the Departments of ${ }^{\mathrm{a}}$ Cardiac Surgery and ${ }^{\mathrm{b}}$ Thoracic Surgery, Nagoya University Graduate School of Medicine, Nagoya, Japan.

Disclosures: The authors reported no conflicts of interest.

The Journal policy requires editors and reviewers to disclose conflicts of interest and to decline handling or reviewing manuscripts for which they may have a conflict of interest. The editors and reviewers of this article have no conflicts of interest.

Received for publication Sept 23, 2020; revisions received Sept 23, 2020; accepted for publication Sept 24, 2020; available ahead of print Oct 3, 2020

Address for reprints: Toyofumi F. Chen-Yoshikawa, MD, Department of Thoracic Surgery, Nagoya University Graduate School of Medicine, 65 Tsurumai-cho, Showa-ku, Nagoya 466-8550, Japan (E-mail: tyoshikawa@med.nagoya-u.ac.jp). J Thorac Cardiovasc Surg 2022;164:539-40

$0022-5223 / \$ 36.00$

Copyright (c) 2020 by The American Association for Thoracic Surgery

https://doi.org/10.1016/j.jtcvs.2020.09.110
}

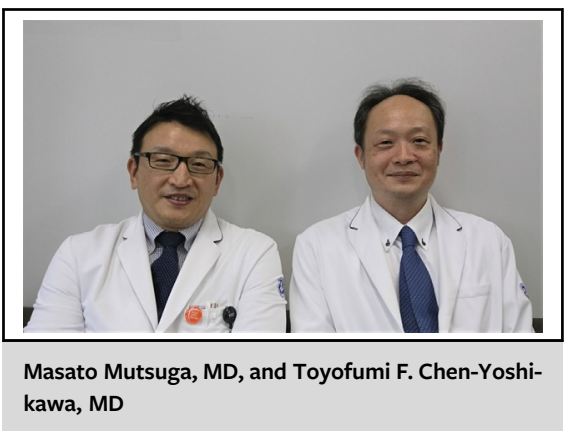

CENTRAL MESSAGE

del Nido cardioplegia has an advantage in that frequent doses are not required, which was proven by histologic evaluation. However, further research focusing on functional outcome is needed.

did not clearly prove that 90 minutes is a real critical point. The authors are therefore encouraged to perform an additional study, which includes a second-dose DNC infusion after more than 90 minutes of ischemia. In addition, the studied hearts were diseased in end-stage heart failure, and therefore any findings should be interpreted with caution. These hearts might not recover after only 1 dose of DNC, and the current dose of DNC also seemed insufficient. Further, the maintenance of myocardial temperature at $18^{\circ} \mathrm{C}$ with a normal saline bath creates uniform hypothermia, which is very different from the local epicardial and endocardial rewarming seen in clinical settings between cardioplegia doses caused by operating room lights, viscera, and venous return. This warm ischemia reduces the amount of safe time between cardioplegia doses. The conclusions should therefore be carefully framed throughout to ensure casual readers are not given the impression that these data support a 90-minute cardioplegia redosing schedule.

Furthermore, the authors can neither correlate the extent of myocardial ischemic injury with likely functional outcome, nor quantify what extent of irreversible mitochondrial or nucleic injury would indicate irreversible myocardial dysfunction because there has been no previous study evaluating the correlation between ultrastructural changes and global function of the myocardium in a human heart. We should wait for research focusing on 
the functional outcome in addition to mere histologic injuries.

Jung and colleagues ${ }^{3}$ show preliminary observational data that indicate that myocardial ischemic injury progresses gradually, and that irreversible ischemic injury of the heart with severe reduced cardiac function begins to occur 90 minutes after initial DNC infusion.

\section{References}

1. Matte GS, del Nido PJ. History and use of del Nido cardioplegia solution at Boston Children's Hospital. J Extra Corpor Technol. 2012;44:98-103.

2. An KR, Rahman IA, Tam DY, Ad N, Verma S, Fremes SE, et al. Systemic review and meta-analysis of del Nido versus conventional cardioplegia in adult cardiac surgery. Innovations. 2019;14:385-93.

3. Jung JC, Kim S-I, Hwang HY, Sohn SH, Choi JW, Chung J-H, et al. Serial ultrastructural evaluation of myocardial ischemic injury after infusion of del Nido cardioplegia in the human heart. J Thorac Cardiovasc Surg. 2022;164:528-35.e2.
See Article page 528.

\section{Commentary: How long can you go with del Nido?}

\author{
Dominick Megna, MD, Pedro Catarino, MD, FRCS, \\ and Joanna Chikwe, MD, FRCS
}

"Another 5 minutes..." Most cardiac surgeons have uttered something to this effect while our perfusionist is hinting that we should redose del Nido cardioplegia. Although clinical experience tends to dictate much of what we do, this holds especially true with our use of del Nido. A multitude of studies have demonstrated equivalent myocardial protection compared with conventional cold blood cardioplegia in adult cardiac surgery, with the advantage of a single dosing regimen. Expert opinion suggests redosing if the ischemic time is likely to extend much beyond $90 \mathrm{mi}-$ nutes. ${ }^{1,2}$ Are we just settling, or are we truly providing optimal myocardial protection? Answering this question in a clinical study is impractical and would require a prohibitive number of patients.

In an attempt to better understand the progression of myocardial ischemic injury and a safe ischemic time after single dose del Nido, Jung and colleagues conducted an ingenious experiment, reported in this issue of the

From the Department of Cardiac Surgery, Smidt Heart Institute, Cedars-Sinai Medical Center, Los Angeles, Calif.

Disclosures: Dr Chikwe has received honoraria from Edwards-Lifesciences and Medtronic for speaker and consulting activity. Drs Megna and Catarino reported no conflicts of interest.

The Journal policy requires editors and reviewers to disclose conflicts of interest and to decline handling or reviewing manuscripts for which they may have a conflict of interest. The editors and reviewers of this article have no conflicts of interest.

Received for publication Oct 17, 2020; revisions received Oct 17, 2020; accepted for publication Oct 20, 2020; available ahead of print Oct 27, 2020.

Address for reprints: Joanna Chikwe, MD, FRCS, Department of Cardiac Surgery, Smidt Heart Institute, Cedars-Sinai Medical Center, Beverly Hills, Los Angeles, CA (E-mail: Joanna.chikwe@cshs.org).

J Thorac Cardiovasc Surg 2022;164:504-1 0022-5223/ $\$ 36.00$

Copyright $₫ 2020$ Published by Elsevier Inc. on behalf of The American Association for Thoracic Surgery

https://doi.org/10.1016/j.jtcvs.2020.10.076
Check for updates

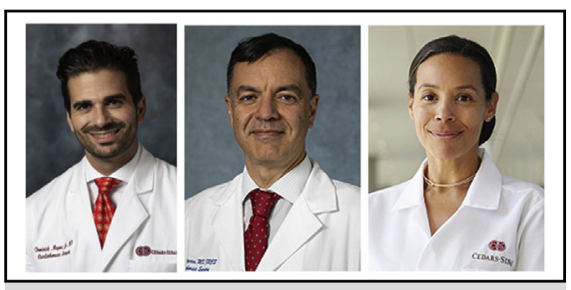

Dominick Megna, MD, Pedro Catarino, MD, FRCS, and Joanna Chikwe, MD, FRCS

CENTRAL MESSAGE

Pathoanatomic data suggest that a single dose of del Nido cardioplegia with myocardial hypothermia provides 90 minutes of safe ischemia.

Journal. $^{3}$ The authors obtained myocardial tissue from the explanted hearts of transplant recipients, which were arrested before explantation with $1000 \mathrm{~mL}$ of del Nido cardioplegia, and then placed in a cold saline bath with the myocardial temperature maintained at $18^{\circ} \mathrm{C}$. Using electron microscopy, they evaluated mitochondrial and nuclear changes that can distinguish between reversible and lethal myocyte damage over the first several hours after the cardioplegia dose. The mitochondrial data are most compelling. Injury scores worsened with longer ischemic time, but even at 90 minutes, only 1 in 100 mitochondria had a lethal injury. The proportion increased 5-fold over the next 90 minutes.

These data provide compelling pathoanatomic support for a single-dose strategy providing up to 90 minutes of safe ischemia. Whether redosing at the 90-minute mark attenuates further lethal injury remains to be established. Of 